\title{
SQUEAK, AN INVISIBLE LABORATORY FOR TEACHERS AS LEARNERS
}

\author{
Luís Valente \\ IEC, University of Minho,valente@iec.uminho.pt \\ António José Osório \\ IEC, University of Minho, ajosorio@iec.uminho.pt
}

PORTUGAL

\begin{abstract}
In this paper we highlight the empowerment of fresh developers challenged to create their own virtual laboratories of learning in Squeak's World. We suggested to a large group of teachers, from all school levels in Portugal, the use of Squeak as a multimedia system, an interface development environment, or simply as a programming language, in order to create new virtual worlds or simulated environments. They were challenged to exploit such a tool, knowing that school and schooling are fine, assuming that we aim to make it better, even if we do not always know what that means.

Keywords: Virtual worlds, children, simulation, creativity, Real Life, invisible laboratory.
\end{abstract}

\section{CURRENT CONTEXT OF INFORMATION AND COMMUNICATION TECHNOLOGY (ICT) IN PORTUGUESE EDUCATION}

\subsection{Context}

The last PISA report (Pinto-Ferreira et al, 2007) about the scientific competences of Portuguese students, published by $\mathrm{GAVE}^{1}$, denotes that students with worse academic results are also those who have more difficulties in the utilization of ICT. Governmental initiatives to provide better ICT access to all students are based on that observation. A recent initiative named Schools, Teachers and Laptops (STL), started by the end of 2006, provided schools above primary level with a technological kit containing fourteen laptops for students' use and ten laptops for teachers, and adding to those a multimedia projector and a wireless access point. And, as a consequence of the Technological Plan for Education, established in 2007, all teachers and $10^{\text {th }}$ grade students got the opportunity to acquire, in financially worthwhile conditions, a laptop with mobile Broadband Internet access.

However, the plans for ICT integration in the curricular activities continue to suffer huge limitations due to the difficulty that schools have in the process of implementation of new activities or because of their own cultural paradigms and

\footnotetext{
${ }^{1}$ GAVE - Ministry of Education's Bureau of Educational Assessment - a free translation of "Gabinete de Avaliação Educacional do Ministério da Educação"
} 
practices of classroom organisation. Very often, computers are installed in laboratories and ICT activities are referred to as computer software lessons. This makes computers become the subject of study instead of becoming instrumental conditions for learning.

\subsection{Barriers to ICT adoption}

From our experience in monitoring the schools' ICT integration process, we find considerable difficulty in the adoption of strategies for the use of new technologies.

The Ministry of Education's recent initiative seems to be insufficient to change the situation and it is clear to us the inability to attract teachers into adopting ICT in teaching. Year after year, the Portuguese teachers had training in technology areas, but the assessment structures and the career progression mechanisms do not sufficiently value the professional training in areas that are not specific to the teaching specialization.

Moreover, the technocentric perspectives refuted by Seymour Papert are commonly adopted. We commonly verify that ICT activities are simply the ones proposed by ICT curriculum teachers, and often other teachers assume they do not have enough knowledge or skills to use ICT in their teaching.

From our point of view, this lack of confidence and low self-esteem could be overcome with more eclectic policies for the integration of technologies.

\subsection{Resistance to change}

The main resistance to the change of paradigm relies on a poor reflection about how technology may help to improve the students' academic development. From our observation, sharing knowledge, resources and strategies is also difficult. But, to be fair, we cannot ignore that education in our country has experienced a large uncertainty in terms of guidelines in recent years. The reforms and counter-reforms have succeeded at such high a rhythm that we have had 12 different Education ministers in the past twenty years.

Resistance is a chronic feature of our society and the direct relation of students' success with the teacher's performance led teachers to ignore the most constructivist methodologies in favour of more traditional practices in which they feel safer. Associating the uncertainty factor to which we referred to the constant agitation in Portuguese education, we can understand why the less entrepreneur ones tend to adopt less risky projects and practices. When the most entrepreneur teachers do not get the expected success, they become easy targets for the most sceptical and conservative ones and the education system does not protect them either.

\subsection{Reprinting the analog model}

Despite the recognition by all of those responsible for education that new technologies require new methodologies, the inability to innovate and the lack of research lead to the replication of the analog model when designing and implementing the use of ICT in education. This attitude is feeding a certain disinterest in the students who are fascinated by the novelty of console games, the interactive features of mobile devices and the engaging activities offered by many online sites. 
While teachers are adopting static electronic presentations, for example, or are using primarily the e-learning platforms as repositories of teaching notebooks (Valente and Moreira 2007), students are succumbing to the offers from Real Life (Osório 2007) which is taking them into immersion and into performance roles that the school does not encourage or tolerate. They become winners, clever and creative individuals outside school.

The reward of success denied by the school is easily obtained through the online services available on $3 \mathrm{G}$ mobile phones or in the cybercentres right in front of schools.

In a pseudo-attitude of innovation and commitment to change the paradigm, the school has systematically ignored, for decades, research evidence from the most remarkable educational researchers on the field of technology integration in education. Seymour Papert, for example, has been insatiable in alerting to the dangers of technocentric teaching; Alan Kay proposes creative and innovative approaches for children to learn with computers (Dynabook), since the 1960s. Nicholas Negroponte has partially jumped into the reality of a dream world where each child can have his/her own computer and Allison Druin (Druin and Inkpen 2001), using a paraphrase of the Papertian idea of computers' invisibleness, suggests that they need to be "seamlessly infused into the school's environment, activities and culture", while Kirschner, Sweller and Clark (Kirschner, Sweller et al. 2006) agree on the lack of minimal guidance learning with ICT. Yet the school continues to show arrogance regarding the most creative proposals it is offered.

\subsection{Computers as curriculum contents}

Our consultancy activity in the area of ICT enabled us to note, for example, a very strong tendency to focus the learning on the physical resources; schools often promote activities more related to equipment than to strategies for their use. Learning Moodle or doing PowerPoint are very common expressions in the projects for ICT integration. It is not unusual to find exploration activities focused on the technical characteristics of the computers or other technical resources. The main rules for the use of equipment and ICT spaces are sometimes genuine obstacles to their use, ignoring its advantage to value learning. In some cases the aim seems to be to preserve the computer at any cost as if one were preserving a rare book by not touching or opening it.

It is a frequent concern of the Heads of schools to lock the computers they have in rooms, misnamed laboratories, in which they are then subject to regulations that exclude the computers' natural and spontaneous use. In the STL initiative we mentioned before, any teacher was enabled with sufficient resources to use ICT in any subject. However, in many cases, schools have stuck these computers in a room/laboratory, inhibiting healthy ICT adoption by the educational community as suggested, among others, by Alison Druin (Druin and Inkpen 2001). In many cases, the importance of having certain equipment seems to be more valued than the concern related to taking advantage of it.

In such a context, but believing that we are in the vanguard of technology, a proactive attitude towards the use of information and communication technologies in education seems to be necessary. We approached these issues by studying, translating and developing the Squeak system for the conception and construction of virtual laboratories for learning. 
As stated by Sussman \& Wisdom (2002), we are concerned with the use of computers not purely as an aid to the visualization or numerical computation but as a programming tool in "a functional style to encourage clear thinking. Programming forces one to be precise and formal, without being excessively rigorous" (p. 2).

\section{THE SQUEAK SYSTEM}

Squeak is a system for object-oriented programming, developed at Apple and tested in Disney. It combines the capabilities of the SmallTalk language with the easiness of an environment based on the visual metaphor of drag and drop. Perfectly suitable to inexperienced users, Squeak begins to make sense to us, with the contributions of various communities of users encouraged by Alan Kay through the Squeakland portal and the interest drawn by the initiative OLPC (One Laptop per Child).

Squeak is the implementation of a proposal on how we can use computers to interact with information, to create our own knowledge, emphasizing the importance of the principles from the Dynabook's ideas that Alan Kay advocates.

In an interview granted to "The Book and the Computer", Alan Kay explains his Dynabook concept: "a portable interactive personal computer, as accessible as a book". This device, that could connect to a network and provide its users with text, viewing of images, video and audio, is considered to be the first draft of the personal computer and laptop, but only still a dream.

While a multimedia system, by allowing kids programming their own play, the Squeak Etoys developed by Kay's team at ViewPoints Research Institute, opens a world of possibilities for exploration and experimentation within all areas of knowledge, exceptionally visible in models' simulation and representation, as stated by Allen-Conn \& Kim Rose (2003) in the book Powerful Ideas in the Classroom.

However, our difficulty to abandon the traditional models and interfaces often prevents us from seeing the world of Squeak beyond the blank screen.

\section{THE SQUEAKLÂNDIA PROJECT AND COMMUNITY}

\subsection{The Squeaklândia project}

Squeaklândia (http://www.squeaklandia.pt) is the first community of Squeak users in Portugal, emerging from an academic project at the University of Minho. Aiming to enable its use by a large number of teachers and students we have translated the English version of Squeak into Portuguese, because we found in Squeak the possibility to profit from the use of open software. Behind this option is the additional value brought about by Web 2.0 features such as the final user's ability to reconfigure the interface. Our reflection about prior observations and experiences with teachers and schools made us propose the use of Squeak as a multimedia system, an interface development environment, or a programming language to create and to design virtual learning laboratories.

In the summer of 2007 , in collaboration with seven schools and two teacher training centres, we provided a Squeak Free Course to the community. Consequently, we also developed a virtual community (web site plus Moodle 
instance) of virtual laboratories' developers where the software is available for download and where we want to provide some examples of projects made with Squeak.

\subsection{Squeak Online Course}

The enthusiasm shown by teachers while programming their first "toys" in Squeak made us build a learning space in our Web site. In late December 2007, we began to accept registrations for the first fully online course on Squeak. This is a selfsupported training course built up in Moodle using video lessons, tutorials and discussion forums. In a week 280 candidates signed up to join it.

In this course we present the system and teach some principles on programming with Squeak, mainly by working with movement scripts. The contents are the most basic characteristics of the system: learn how to create and save a project in Squeak; learn to get objects in motion and control them with a virtual joystick; learn how to use simple conditioned events.

The course is organized in modules that are supported by diverse information documents, such as manuals for download in PDF format, resources' sequence in HTML format created in the e-learning platform and videos explaining the necessary procedures for doing small projects.

The modules are designed to allow self-learning and respecting a gradual increase in difficulty. Support is given to students through discussion forums and a system of pre-scheduled online chat. The contents are presented once every two weeks and at the end of the course the trainees should upload a project on which what their learning is implemented.

Then the projects available in a database's internal platform are evaluated by the course teacher, and are made accessible to all other participants in an attempt to promote the sharing of ideas and resources. Likewise we created a system to collect suggestions for new projects which we expect to be a birthplace for future Squeak projects.

We also proposed a space to gather project ideas by using an HTML form, trying to encourage all participants, in a kind of online brainstorming activity, to share their ideas.

\subsection{Teachers as learners}

Since the community is completely open, it is not possible to accurately characterize its members, but in the beginning of the course we asked the participants to fill in a short questionnaire that allowed us having a clearer idea of who is interested in Squeak.

By the time we are writing this paper only 133 participants have answered the questionnaire. From this information we can see that the majority of the participants are female $(52 \%)$ and that the most expressive age group is from 46 to 50 years, as follows: $4 \%$ are under 30 years old, $17 \%$ are between 31 and 35 years old, $22 \%$ are between 36 and 40 years old, $19 \%$ are between 41 and 45 years old, $23 \%$ are between 46 and 51 years old and $17 \%$ are over $51.5 \%$ of the participants are teaching in higher education or not teaching at all. 
In spite of there being a minority of pre-school teachers (1\%) and primary school teachers $(9 \%)$, there are teachers belonging to all groups of the Portuguese education system with special emphasis on ICT teachers (17\%) who form the largest group.

\subsection{Reasons given for having signed up}

One of the questions we asked the participants is their reason for signing up. Although we still did not perform a proper statistical treatment, we noted that $25 \%$ refer reasons related to the desire to learn, $17 \%$ say that they have signed up by curiosity, $21 \%$ state they are looking for new things, $23 \%$ affirm having signed up because they are concerned with providing their students with new opportunities for learning and $11 \%$ declared having signed up because they like technology.

Perhaps we can realise here a concern with the quality of professional performance and discover some very important proactive attitudes to reach the success through new approaches in education, but the short time during which the experience is running does not give us the basis we need to go deeper in our assessment.

\section{SQUEAK ACTIVITIES}

\subsection{Proposed exploitation}

In the online course participants were taken to explore the potential of Squeak related to the movement and its control through scripting. The aim was not exactly to explore practical applications but to highlight the easiness of the programming, associated with the learning potential of Squeak. It is worth to mention that at an earlier trial workshop on Squeak, held a few months ago, we were confronted with the observation that the word "programming" stated at the activity title was discouraging for candidates seeking information before subscribing.

The tasks of this first course imply designing and building a virtual laboratory, even incipient or embryonic, allowing learning how to program without even using the terms and concepts associated with traditional programming.

The students of this course were required to submit a draft project at the end of the course to show their achievements.

\subsection{The first Squeak projects}

As the projects were being transferred to the platform we found they do not vary all that much from the general application suggested in the course contents, but there are some attempts to use creativity which bring us high hope on the impact of the course.

Thus some projects are combining the movement of rotation with the linear displacement of everyday life objects, verifiable for instance in cycling, in the movements of joggling in circus (see Figure 1), in the handling of the solar system's elements and so on. Other projects try to represent the movement of animals in nature such as birds, fish and domestic mammals and motorized transport vehicles, such as boats and aircraft. 
The use of a kind of joystick to control movement was also already submitted, applied to most common examples as car circuits or to discover the pathways in fictional labyrinths or an animal's tracks in nature. Another proposal encouraged the representation of fables' elements: The Tortoise and the Hare.

A number of projects can be included in the category of "testing" learning achieved in other environments, such as healthy food and the sorting out of domestic waste.

We have projects in which the user interaction is reduced to acting in a start/stop button or to the exploitation of curriculum contents. One of such projects simulates a voyage discovering Brazil and another shows the movement of the sails of a windmill, for example.
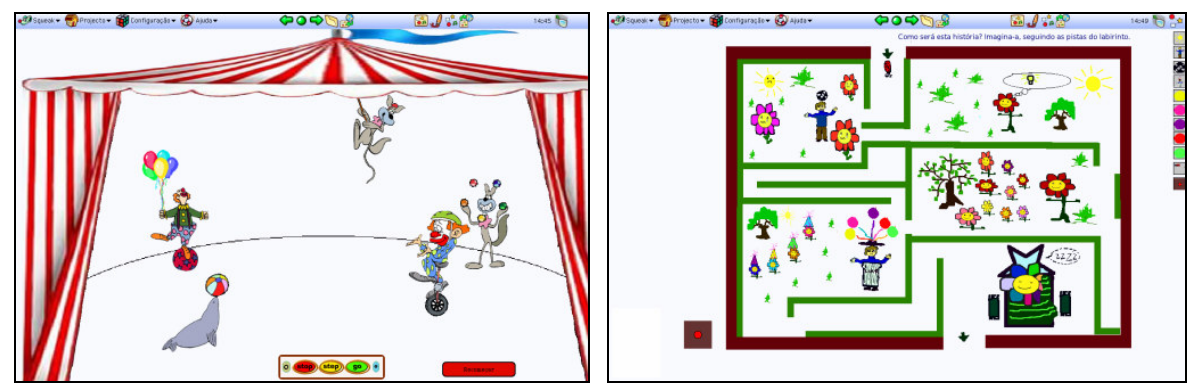

Figure 1- Squeak projects presented for assessment

Initially, as they did not have enough experience, participants showed a tendency to replicate the projects which were presented to them as examples, but later they started trying more complex and interesting simulations. We detected this feature in the work of participants that had several projects, and in those cases, the first projects were always less creative and denoted less personal investment than the subsequent ones.

In all projects participants tried to simulate curriculum content issues, using Squeak as an invisible laboratory. While learning at their pace, independently, trying new activities and discovering the basics of programming with Squeak, these teachers highlighted many of the thoughts valued in education.

\section{CONCLUSION}

The greatest difficulty in learning how to use a new system such as Squeak seems to be directly connected to the learner's ability (or inability) to explore available documents and to understand and deconstruct them. Very often the help requested to the course trainer consisted in solving small problems, such as the upgrade of plugins in common Web browsers or the location of downloaded files.

We found that those participants, who take longer than most to reach the features, capabilities and the appropriate way to use the software, express some rejection attitudes towards Squeak. Firstly, they start comparing the final "products" they get from Squeak with the products they get from other systems they are already used to, such as "PowerPoint" or "Flash" clips, ignoring the added value features brought about by the new tool. 
Most of these teachers have a critical perspective of Squeak, close to that described by Seymour Papert in the paper "Computer Criticism vs. Technocentric Thinking", meaning that they expect something from Squeak but not what they can do with Squeak.

It is worth to mention that many of the enrolled participants in this community have an evident interest in computers and technology but low expertise in operating it or in its educational use, which gives them a perspective clearly different from the perspective that Papert defends. We also noted that "insecurity sometimes makes a technical object loom too large in their thinking... their intimidation and limited technical understanding often blind to the fact that what they see as a property of 'the computer' is often a cultural construct'.

However, some participants are beginning to ask questions related to situations not yet tested, using a hypothetical-deductive language: if $I$ use the " $x$ " characteristic can I get the " $y$ " effect? As they progress in the acquisition of knowledge and understanding the way Squeak language works, Squeak learners seem to discover original, different features allowing us speculating that they are starting to realize Squeak's power.

Most recently we reached a way to embed the Squeak project as a multimedia filter in the Moodle platform, and we hope this development can improve Squeak's and Moodle LMS's integration. Moodle is a strong trend in Portuguese Schools and this advance gave us the possibility to create a database functionality that launches automatically every Squeak project into a web plug-in.

Even though we are at an early stage of our study, we are gathering indicators (the high number of course participants, the participation level in online activities and discussions, the questions posted to the trainer, the participants' concern with design) pointing to the development of a research attitude in our Squeaklândia community participants. Therefore we will continue to maintain our Squeak project visible aiming to enable Portuguese teachers to learn, experiment and research in invisible programming laboratories.

\section{REFERENCES}

Allen-Conn, B. J. and K. Rose (2003). Powerful Ideas in the Classroom. Glendale, Viewpoints Research Institute, Inc.

Druin, A. and K. Inkpen (2001). "When are Personal Technologies for children?" Personal and Ubiquitous Computing $\mathbf{5}(3)$.

Kirschner, P. A., J. Sweller, et al. (2006). "Why Minimal Guidance During Instruction Does Not Work: An Analysis of the Failure of Constructivist, Discovery, Problem-Based, Experiential, and InquiryBased Teaching." Educational Psychologist 41(2): 75-86.

Osório, A. J. (2007). Real Life. Personal communication. Braga.

Papert, Seymour (1987). Computer Criticism vs. Technocentric Thinking. Educational Researcher 16 (I)

Pinto-Ferreira, C., A. Serrão, et al. (2007). PISA 2006 - Competências Científicas dos Alunos Portugueses. Lisboa, GAVE - Gabinete de Avaliação Educacional.

Sussman, G., Wisdom, J. (2002). The Role of Programming in the Formulation of Ideas. AI Memos (1959 - 2004). MIT - Artificial Intelligence Laboratory. http://hdl.handle.net/1721.1/6707

Valente, L. and P. Moreira (2007). Moodle: moda, mania ou inovação na formação? - Testemunhos do Centro de Competência da Universidade do Minho. Challenges 2007, Braga, Centro de Competência da Universidade do Minho. 